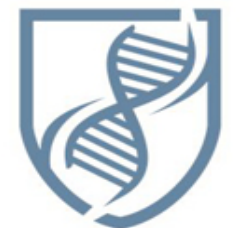

Journal of Bioscience and Applied Research

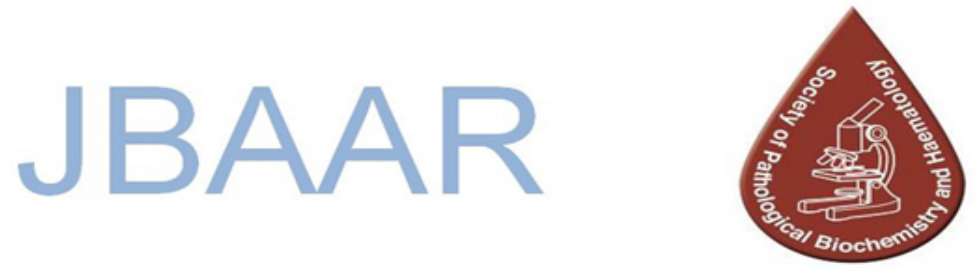

WWW.JBAAR.ORG

\title{
Interleukin-1 receptor antagonist gene polymorphism and obesity: a pilot study from Egypt
}

\author{
Sabah Farouk, Wael Abdel-Mageed, Mahmoud Aly \\ Molecular Biology Department. Genetic Engineering and Biotechnology Research Institute \\ (GEBRI), Sadat City University, Sadat City, Menoufia, Egypt
}

(Corresponding author e-mail. mahmoudm0346@gmail.com)

\begin{abstract}
The main adverse consequences of excess bodyweight are cardiovascular disease, type II diabetes, and several cancers. IL-1Ra serum concentration has been reported earlier to increase in human obesity and it is therefore assumed that the polymorphism of IL-1Ra may influence cytokine production. The study was designed to investigate whether the IL-1Ra polymorphism was associated with obesity. A total number of 66 individuals; 20 normal (BMI $<25 \mathrm{Kg} / \mathrm{m} 2$ ), 20 overweight (BMI 25-29.9 Kg/m2) and 26 obese (BMI More than $30.0 \mathrm{Kg} / \mathrm{m} 2$ ) were enrolled in this study. Genotyping was performed using a polymerase chain reaction PCR amplification of the intron-2 fragment harboring a variable number of tandem repeat (VNTR) nucleotide sequences 86 bp of tandem repeat. The PCR products were separated on $2 \%$ agarose gel. Statistical analysis was performed using SPSS software (version 11.5). The genotype and allelic frequencies showed a significantly difference between normal vs. overweight and normal vs. obese (p-values: $0.001 ; 0.0001 ; 0.0018$ and 0.001 respectively). Although, The presence of Allelic frequencies for Allele I between normal vs. overweight and normal vs. obese showed $>2$ folds risk in overweight and $>3$ folds in obese $(\mathrm{OR}=2.3$; 95\% $\mathrm{CI}=0.796-8.620$ \& $\mathrm{OR}=2.1 ; 95 \% \mathrm{CI}=0.972-10.265$ respectively). Allele II between normal vs. overweight and normal vs. obese showed $>3.5$ folds risk in overweight and $>1.5$ folds in obese (OR=3.45; 95\% CI=0.836-9.210 \& OR=1.63; 95\% $\mathrm{CI}=0.892-9.11$ respectively) and Allele $\mathrm{V}$ between normal vs. overweight and normal vs. obese showed $>2$ folds risk in overweight and $>1.5$ folds in obese (OR=1.99; $95 \%$
\end{abstract}

$\mathrm{CI}=0.821-9.10 \quad \& \quad \mathrm{OR}=1.95 ; \quad 95 \% \quad \mathrm{CI}=0.882-8.975$ respectively).This may suggest that IL-1Ra appears to be induced by inflammatory stimuli as well as obesityassociated factors. This is relatively a pilot study; but nevertheless, may assist in identifying the pathophysiological cause for obesity

Keywords: IL-1 Ra Polymorphism, Body mass index, Obesity

\section{Introduction}

Obesity is an important cause of disease and mortality worldwide. It's an increasing common health problem that raises the risk for type 2 diabetes, hypertension and some forms of cancer (Clover et al. 2005). It is defined as a body mass index (BMI) of greater than $30 \mathrm{~kg} / \mathrm{m} 2$ and is associated with many diseases such as type 2 diabetes mellitus, hypertension, coronary heart disease, dyslipidemia, gall bladder diseases, infertility and certain forms of cancer (Smith, 2001). As a difficult disease, it is determined by multiple genetic and environmental factors, including physiological and behavior cultural. Cytokines appear to be major regulators of adipose tissue metabolism (Ganss, 2004). Expression studies show that adipocytes can synthesize tumor necrosis factor alpha (TNF- $\alpha$ ) and several interleukin (IL) notably IL-1 $\beta$ and IL-6. IL-1 $\beta$ is well known to suppress adipocyte differentiation and lipoprotein lipase expression and activity by inhibiting the expression of fatty acid transport protein in adipose tissue (Mandrup et al. 1993 \& Juge et al. 
2003). In addition, IL- $\beta$ is significantly more potent relative to TNF- $\alpha$, and other cytokines ( Uland et al. 2010). IL-1Ra is markedly up regulated in the serum of obese patients is correlated with BMI and insulin resistance (Hung et al. 2005). It is an important regulator of adipogenesis, food intake, and energy expenditure (Reutter, 2007). Interleukin 1 (IL1) is a regulator on inflammation and energy homeostasis. Previous studies investigated that the IL1 system was contributed to metabolism (Uland et al. 2010 \& Nixon et al. 2005). Interleukin 1 receptor antagonist (IL1RN) is included in the IL1 system. IL1RN is an acutephase protein. IL1RN has an anti-inflammatory function by blocking the receptor for IL1A and IL1B without exerting any biological effect (Van Poppel et al. 2014 and Saltevo et al, 2008). IL-1 consists of IL-1 $\beta$ and IL-1Ra. Genes for IL-1 $\beta$ and IL-1Ra are located on $2 q 14-21$. Five alleles of the IL-1Ra gene have been described, consistent to 2,3,4,5 and 6 copies of an 86-base pair sequence repeats placed in intron-2 (Mandrup et al. 1993). IL-1Ra is an endogenous inhibitor that antagonizes many of the biological actions of IL-1 $\beta$ by competitive inhibition ( Um et al. 2004). In addition, IL-1Ra serum concentrations are highly increased in human obesity and that its concentrations decrease after weight loss ( Brum et al. 2007). Therefore, it is likely that polymorphism of the IL1 Ra be affected due to variation in cytokine production. Previous study revealed that IL1Ra is associated with obesity (Nixon et al. 2005). IL1Ra showed high level in the serum of obese patients and overexpressed in white adipose tissue ( land graph et al. 2015). The IL1RN knockout mice get leanness and obesity resistance. It indicated that IL1Ra is an important regulator of adipogenesis, food intake, and energy expenditure in obesity (Cui et al. 2015). In this study, we hypothesized IL-1Ra gene as a candidate gene for obesity, so investigate whether polymorphisms of the IL-1Ra gene are associated with the development of obesity in a cohort of Egyptian population.

\section{Materials and Methods Patients:}

A total number of 65 Men (age range, 24-96) recruited from Menoufiya government, were included in the present study. The patients in the study had no history of metabolic disorder, renal, liver, hematological disease or any other disorder other than obesity. The subjects were divided into three body mass index (BMI) groups according to World The clinical characteristics of all the patients are given in Table 1 . The frequency distribution of different genotypes and allelic frequencies in normal, overweight and obese are shown in Table 2 . The genotype distribution of IL-1Ra polymorphism was in Hardy-Weinberg equilibrium. The bands on $2 \%$ agarose gel revealed variable number of tandem repeats. The fragment sizes for IL-1Ra do not correspond with the number of repeats as some extra bases are also amplified along with the repeats. In the present study, we have not found allele III (500 pb), allele IV (325 bp), allele and VI (154 bp) in any of the three groups. The genotype and allelic frequencies showed a significantly difference between normal vs. overweight and normal vs. obese (p-values: 0.001; 0.0001; 0.0018 and 0.001 respectively). Although, The presence of Allelic frequencies for Allele I between normal vs. overweight and normal vs. obese showed $>2$ folds risk in overweight and $>3$ folds in obese $(\mathrm{OR}=2.3$; 95\% CI=0.796-8.620 \& $\mathrm{OR}=2.1 ; 95 \% \mathrm{CI}=0.972-10.265$ respectively). Allele II between normal vs. overweight and normal vs. obese showed $>3.5$ folds risk in overweight and $>1.5$ folds in obese $(\mathrm{OR}=3.45$; 95\% CI=0.836-9.210 \& OR=1.63; 95\% $\mathrm{CI}=0.892-9.11$ respectively) and Allele $\mathbf{V}$ between normal vs. overweight and normal vs. obese showed $>2$ folds risk in overweight and $>1.5$ folds in obese ( $\mathrm{OR}=1.99 ; 95 \%$ $\mathrm{CI}=0.821-9.10 \quad \& \quad \mathrm{OR}=1.95 ; \quad 95 \% \quad \mathrm{CI}=0.882-8.975$ respectively).

Health Organisation (WHO) definitions was used: Normal (BMI <25 Kg/m2), overweight (BMI 25-30 Kg/m2) and obese $(\mathrm{BMI} \leq 37.0 \mathrm{Kg} / \mathrm{m} 2)$. In the present study BMI ranged between 22 and $50 \mathrm{Kg} / \mathrm{m} 2$. Informed consent was obtained from the patients and the controls participating in the study.

\section{Phenotype measurements:}

BMI was calculated as weight $(\mathrm{Kg}) /$ height $(\mathrm{cm})$ square. BMI: Body Mass Index, SBP: Systolic Blood Pressure, DBP: Diastolic Blood Pressure, FBS: Fasting Blood Sugar test, IRA: Interleukin 1 Receptor Antagonist, BI: Basal Insulin (measured at its greatest gluteal protuberance).

\section{DNA extraction:}

Five $\mathrm{ml}$ of blood was collected in EDTA vials from cases and controls. DNA was extracted from blood lymphocytes using 'salting out' method (13). IL-1Ra VNTR genotyping: The primer sequences used were: forward, 5-CTCAGCAACACTCCTAT-3; reverse, 5TCCTGGTCTGCAGGTAA-3. The region within the second intron of IL-1Ra gene contains variable number of tandem repeat (VNTR) of 86 base pairs. The PCR products of 410 bp (allele I= four repeats), 240 bp (allele II= two repeats), 500 bp (allele III= five repeats), 325 bp (allele $\mathrm{IV}=$ three repeats), $595 \mathrm{bp}$ (allele $\mathrm{V}=$ six repeats) and 154 bp (allele $\mathrm{VI}=$ one repeat) were analyzed by electrophoresis on a $2 \%$ agarose gel (14).

\section{PCR conditions:}

Initial denaturation, $95^{\circ} \mathrm{C}$ for 5 min followed by $95^{\circ} \mathrm{C}$ for $30 \mathrm{sec}$, annealing at $58^{\circ} \mathrm{C}$ for $30 \mathrm{sec}$, extension at $72^{\circ} \mathrm{C}$ for $30 \mathrm{sec}$ for 30 cycles and a final extension at $72^{\circ} \mathrm{C}$ for $10 \mathrm{~min}$. The size of PCR product was determined using a 100-bp DNA ladder (Roche, Germany). The molecular weight of each band was determined by using software in Alpha Imager 1220 version 5.5 programme.

\section{Statistical Analysis:}

Statistical analysis was performed using the HardyWeinberg Equilibrium Calculator test and compare the genotype and allelic frequency distribution in lean, overweight and obese with the SPSS software (version 11.5). Allele and genotype frequencies were compared using a $2 \times 2$ contingency table using Fisher's exact test. The mean concentration of all numerical values was tested by the Student $t$-test or ANOVA test. $P$ - value $<0.05$ was considered statistically significant. 


\section{Results}

The clinical characteristics of all the patients are given in Table 1. The frequency distribution of different genotypes and allelic frequencies in normal, overweight and obese are shown in Table 2. The genotype distribution of IL-1Ra polymorphism was in Hardy-Weinberg equilibrium. The bands on $2 \%$ agarose gel revealed variable number of tandem repeats. The fragment sizes for IL-1Ra do not correspond with the number of repeats as some extra bases are also amplified along with the repeats. In the present study, we have not found allele III (500 pb), allele IV (325 bp), allele and VI (154 bp) in any of the three groups. The genotype and allelic frequencies showed a significantly difference between normal vs. overweight and normal vs. obese (p-values: 0.001; 0.0001; 0.0018 and 0.001 respectively). Although, The presence of Allelic frequencies for Allele I between normal vs. overweight and normal vs. obese showed $>2$ folds risk in overweight and $>3$ folds in obese $(\mathrm{OR}=2.3$; 95\% $\mathrm{CI}=0.796-8.620$ \& $\mathrm{OR}=2.1 ; 95 \% \mathrm{CI}=0.972-10.265$ respectively). Allele II between normal vs. overweight and normal vs. obese showed $>3.5$ folds risk in overweight and $>1.5$ folds in obese $(\mathrm{OR}=3.45 ; 95 \% \mathrm{CI}=0.836-9.210$ \& $\mathrm{OR}=1.63 ; 95 \%$ $\mathrm{CI}=0.892-9.11$ respectively) and Allele $\mathbf{V}$ between normal vs. overweight and normal vs. obese showed $>2$ folds risk in overweight and $>1.5$ folds in obese $(\mathrm{OR}=1.99$; $95 \%$ $\mathrm{CI}=0.821-9.10 \quad \& \quad \mathrm{OR}=1.95 ; \quad 95 \% \quad \mathrm{CI}=0.882-8.975$ respectively).

\section{Discussion}

Obesity is a major chronic disorder affecting 25-45\% adults in Egypt. It is a complex metabolic disorder that is genetically determined. There are many candidate genes for obesity that affect the adipocyte differentiation ( Struph et al. 1994). The present study was undertaken to determine whether VNTR polymorphism of IL- 1Ra gene was associated with obesity in Egyptian population. We compared the genotype frequencies of lean with that of overweight and obese groups and found no significant association. Though the $\mathrm{p}$-value was non-significant between lean and obese, Odd's ratio when calculated, higher risk $>2$ folds in overweight and $>3$ folds in obese ('high producers' of IL-1Ra) was observed. Our results are in accordance to Um et al. 2004 \& Escapar et al. 2004, who also found no relationship between IL-1Ra polymorphism and BMI in Korean population. Proinflammatory cytokines like IL-1 $\beta$ and TNF- $\alpha$ suppresses adipose differentiation and lipoprotein lipase expression. Bruun et al. 2005, demonstrated that TNF- $\alpha$ and IL-1 $\beta$ are able to regulate the production and release of leptin from human adipose tissue fragments in vitro ( Sugiyama, 2009), In addition, Plata- Salaman et al. (2008) reported that obese rats showed a significantly stronger anorexia in response to the central administration of IL$1 \_$Ra than do lean controls. These findings support our hypothesis that the increased basal expression of IL-1_Ra as a consequence of the polymorphism can be protective against being overweight but the presence of genotype II/II of IL-1Ra that is a 'high producer' therefore counteracts the properties of IL-1_Ra and may thus increase the adipocyte differentiation and promote lipogenesis in adipose tissue (Luheshi et al. 2005) . IL-1Ra also plays a regulatory role in energy homeostasis. Luheshi et al. 2005, demonstrated that the hypothalamic effects of leptin depend heavily on the action of IL- 1 and that the injection of IL-1Ra into the cerebral ventricles inhibited the leptin-induced reduction in food intake as well as the concomitant increase in body temperature by more than $60 \%$ ( Reutter, 2007). As the central resistance to leptin, rather than its deficiency, is the hallmark of most cases of human obesity, a better understanding of the factors involved in the regulation of the hypothalamic sensitivity to leptin is important. Thus, based on these findings, we focused on the association between the polymorphism of IL-1Ra and obesity. However, more knowledge about genetics of obesity is needed in order to prevent it in existing and next generation.

\section{References}

Bruun JM, Stallknecht B, Helge JW, and Richelsen B. (2007). Interleukin-18 in plasma and adipose tissue: effects of obesity, insulin resistance, and weight loss. Eur J Endocrinol, 157(4): 465-71

Cartier Amélie, Lemieux Isabelle, Alméras Nataliem, Tremblay Angelo, Bergeron Jean and Després Jean-Pierre. (2008). Visceral obesity and plasma glucoseinsulin homeostasis: contributions of interleukin-6 and tumor necrosis factor-alpha in men. J Clin Endocrinol Metab, 93(5): 1931-8.

Cui, Jun-Na Luan, Jianping Ye and Shi-You Chen., et al., RGC32 deficiency protects against high-fat diet-induced obesity and insulin resistance in mice. J Endocrinol, 2015. 224(2): p. 127-37.

Francine R. Kaufman (2005). Diabesity: The Obesity-Diabetes Epidemic That Threatens America--And What We Must Do To Stop It. Library Journal, 130(2): p. 108-108

Escobar-Morreale HF, Botella-Carretero JI , Villuendas G, Sancho J and San Millán JL. (2004). Serum interleukin-18 concentrations are increased in the polycystic ovary syndrome: relationship to insulin resistance and to obesity. J Clin Endocrinol Metab, 89(2): 806-11.

Amy Hendel. (2008).Fat Families, Thin Families: How To Save Your Family from the Obesity Trap. Library Journal, 133(10): 116-116.

Ganss Dawn (2004). Health Issues: Obesity in Youth. School Librarian's Workshop, 24(10): 11-12.

Hung J, McQuillan BM, Chapman CM, Thompson PL, and Beilby JP. (2005). Elevated interleukin-18 levels are associated with the metabolic syndrome independent of obesity and insulin resistance. Arterioscler Thromb Vasc Biol, 25(6): 1268-73 
Table (1): Comparison between three groups for clinical characteristics

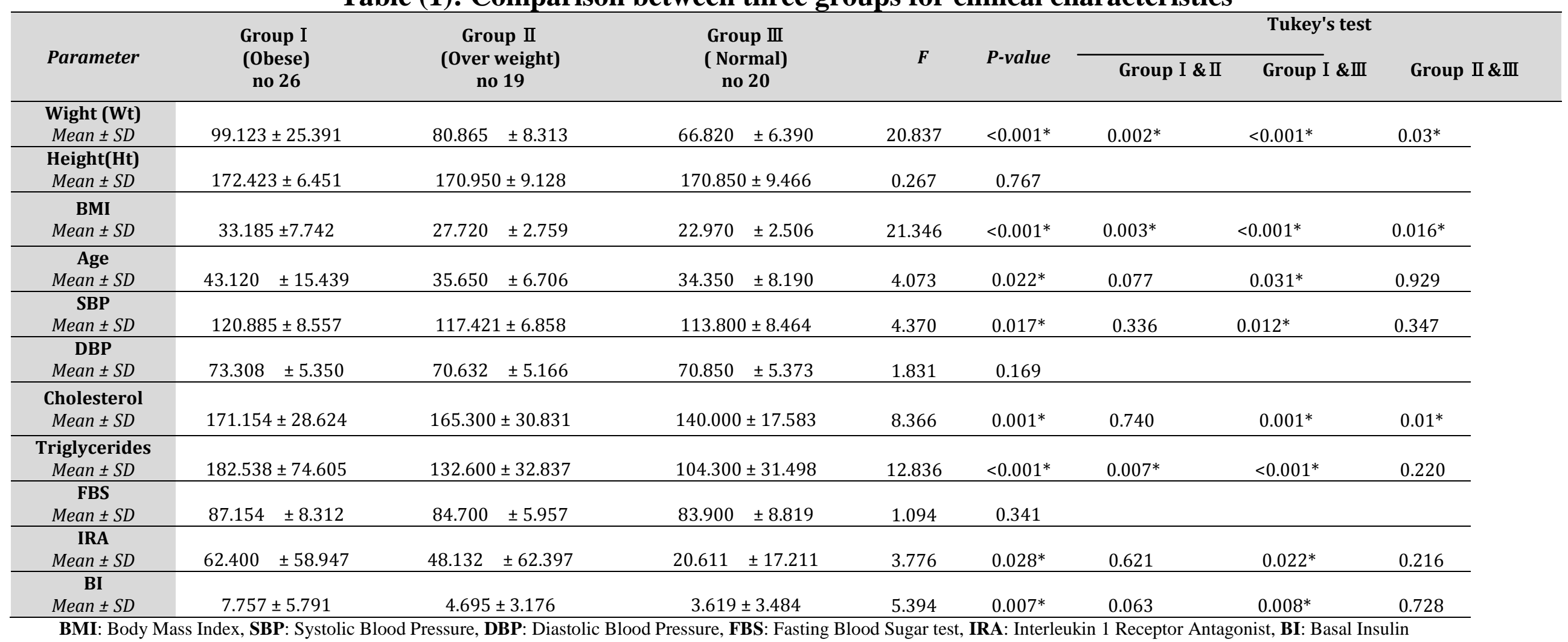




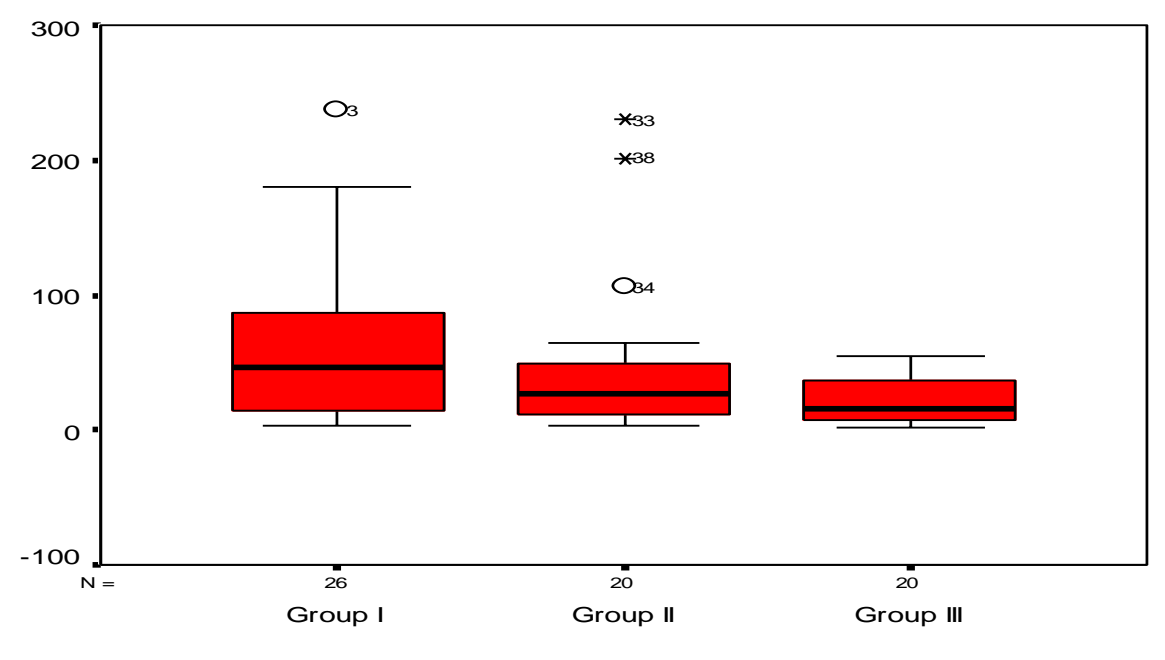

Groups

Figure1. Serum level of Interleukin receptor 1 antagonist in the three different groups .

Data are presented as box plots with line inside the box representing median representing $25^{\text {th }}$ and $75^{\text {th }} \%$ and the lines outside the box indicating $10^{\text {th }}$ and $90^{\text {th }} \%$.

Table (2): The genotype distribution of IL-1Ra polymorphism

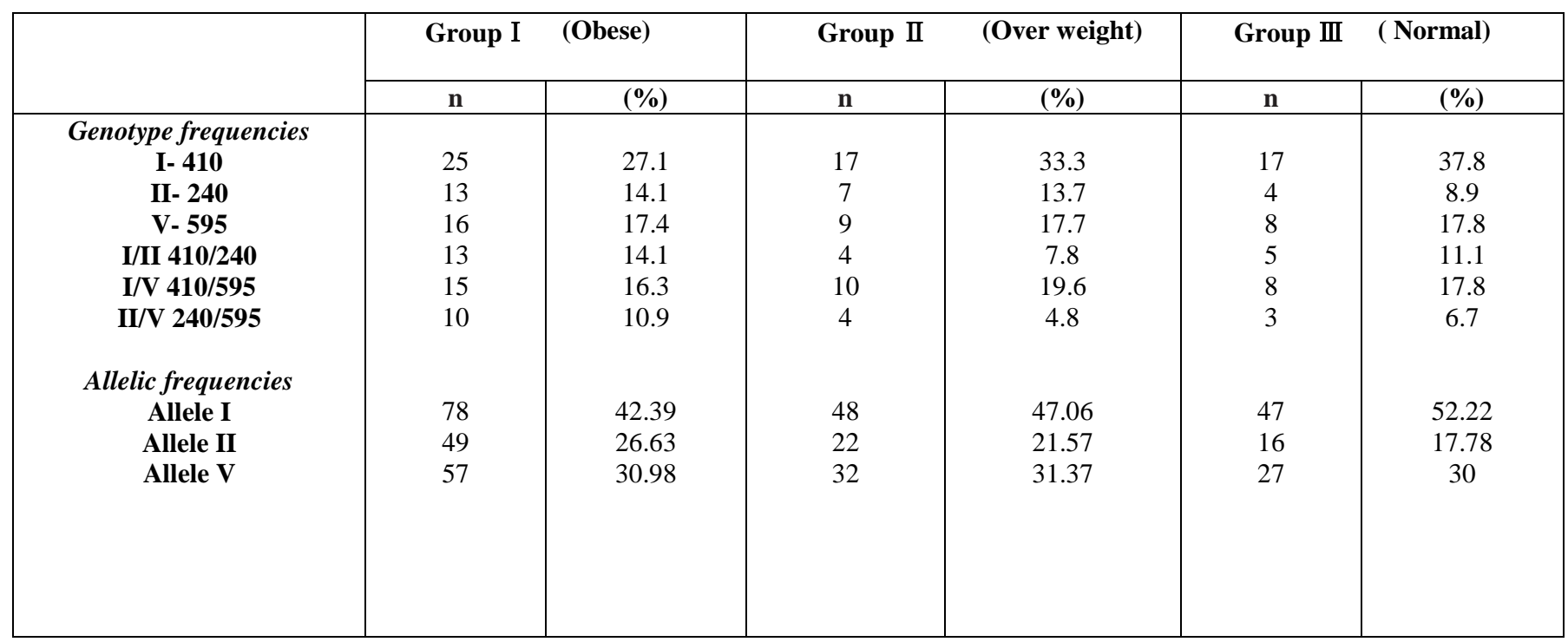

Group I : P. value= 0.001, Group II P. value= 0.0001, Group III P. value $=0$. 
Table (2): The genotype distribution of IL-1Ra polymorphism

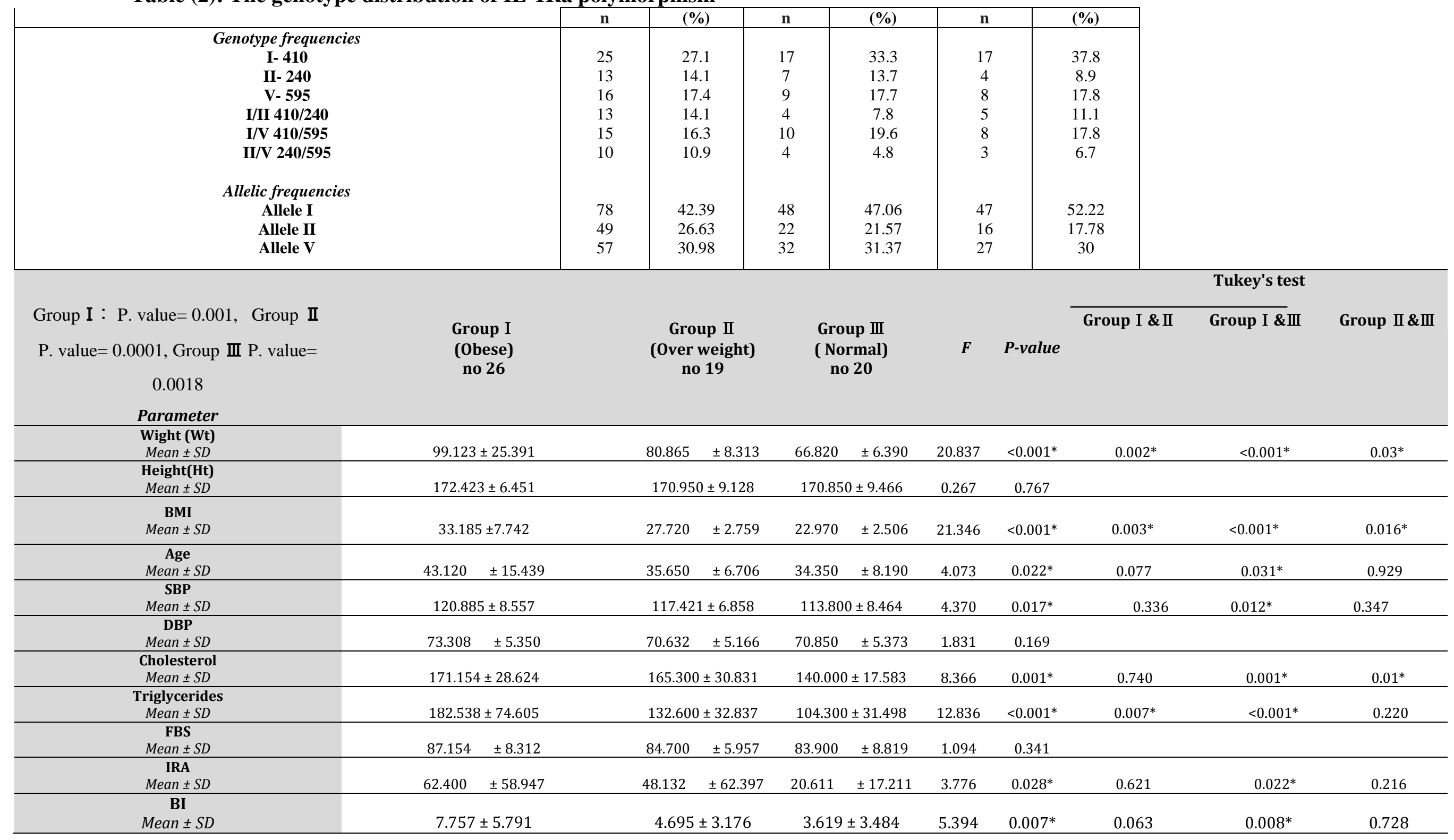


Juge-Aubry CE, Somm E, Giusti V, Pernin A, Chicheportiche R, Verdumo C, Rohner-Jeanrenaud F, Burger D, Dayer JM, and Meier CA.,(2003). Adipose tissue is a major source of interleukin-1 receptor antagonist: upregulation in obesity and inflammation. Diabetes, 52(5): 1104-10.

Klover, P.J., Clementi,A,H. and Mooney, R.A. (2005).Interleukin-6 depletion selectively improves hepatic insulin action in obesity. Endocrinology, 146(8): 3417-27

Landgraf K, Rockstroh D, Wagner IV, Weise S, Tauscher R, Schwartze JT, Löffler D, Bühligen U, Wojan M, Till H, Kratzsch J, Kiess W, Blüher M, and Körner A. (2015). Evidence of early alterations in adipose tissue biology and function and its association with obesity-related inflammation and insulin resistance in children. Diabetes, 64(4): 1249-61.

Mandrup-Poulsen T, Zumsteg U, Reimers J, Pociot F, Mørch L, Helqvist S, Dinarello CA, and Nerup J. (1993).Involvement of interleukin 1 and interleukin 1
antagonist in pancreatic beta-cell destruction in insulindependent diabetes mellitus. Cytokine, 5(3): 185-91.

Nixon AJ, Haupt JL, Frisbie DD, Morisset SS, McIlwraith CW, Robbins PD, Evans $\mathrm{CH}$, and Ghivizzani S. (2005).Gene-mediated restoration of cartilage matrix by combination insulin-like growth factorI/interleukin-1 receptor antagonist therapy. Gene Ther, 212(2): 177-86.

Smith, Mercedes. (2001).Obesity: An American

Epidemic. School Library Journal, 47(10): 81.

Reutter, V.(2007).Obesity in a Bottle. School Library Journal, 53(3): 71-71.
Saltevo J, Laakso M, Jokelainen J, KeinänenKiukaanniemi S, Kumpusalo E, and Vanhala M. (2008). Levels of adiponectin, C-reactive protein and interleukin-1 receptor antagonist are associated with insulin sensitivity: a population-based study. Diabetes Metab Res Rev, 24(5): 378-83.

Strumph PS, Carty SE, Rilo HL, Carroll PB, Ricordi C and Lotze MT. (1994). Interleukin-1 receptor antagonist is not detrimental to human islet cell insulin secretion but decreases insulin content. Transplant Proc, 26(2): 694.

Sugiyama, T., Gardiner,P. and Owen, N.(2009).Associations of Leisure-Time Internet and Computer Use With Overweight and Obesity, Physical Activity and Sedentary Behaviors: Cross-Sectional Study. Journal of Medical Internet Research, 11(3): 31-3.

$$
\text { Ueland T, Fougner SL, Godang K, Lekva }
$$

T, Schurgers LJ, Scholz H, Halvorsen B, Schreiner T, Aukrust P, and Bollerslev J. (2010). Associations between body composition, circulating interleukin-1 receptor antagonist, osteocalcin, and insulin metabolism in active acromegaly. J Clin Endocrinol Metab, 95(1): 361-8. Um, J.Y., Lee, KM and Kim,H.M. (2004). Polymorphism of interleukin-1 receptor antagonist gene and obesity. Clin Chim Acta, 340(1-2): 173-7.

Van Poppel PC, van Asseldonk EJ, Holst JJ, Vilsbøll T, Netea MG,and Tack CJ. (2014). The interleukin-1 receptor antagonist anakinra improves firstphase insulin secretion and insulinogenic index in subjects with impaired glucose tolerance. Diabetes Obes Metab, 16(12): 1269-73. 